\title{
ESPACIOS LIMINALES, FANTASMAS DE LA MEMORIA \\ E IDENTIDAD EN EL TEATRO HISTÓRICO CONTEMPORÁNEO ${ }^{1}$
}

\author{
LIMINAL SPACES, MEMORY GHOSTS AND IDENTITY \\ IN THE CONTEMPORARY HISTORICAL THEATRE
}

\author{
Luisa GARCÍA-MANSO \\ Universiteit Utrecht \\ m.1.garcia-manso@uu.nl
}

\begin{abstract}
Resumen: Los espacios liminales simbolizan la transición entre dos estados diferenciados. Como propuesta de definición y descripción de lo liminal en el espacio dramático, en este ensayo se analiza su construcción en La tumba de Antígona, de María Zambrano; Le retour de Carola Neher, de Jorge Semprún; ;Ay, Carmela!, de José Sanchis Sinisterra y Los niños perdidos, de Laila Ripoll. En estas obras se construyen espacios liminales -tumbas, cementerios, lugares abandonados, escenarios- en los que los fantasmas de la memoria toman cuerpo y se incita al público a asumir el deber de memoria e indagar en la identidad colectiva.
\end{abstract}

Palabras clave: Memoria. Drama histórico actual. Liminalidad. Espacio. Fantasmas.

Abstract: Liminal spaces symbolize the transition between two different

1. Este trabajo se ha realizado en el marco del proyecto de investigación Escrituras, Imágenes $y$ Testimonio en las autoras hispánicas contemporáneas (MINECO, Plan Estatal I+D+i , FFI2015-63745-P). 
states. In this essay I propose a definition and description of these symbolic spaces in theatre, through the analysis of La tumba de Antígona, by María Zambrano; Le retour de Carola Neher, by Jorge Semprún; ;Ay, Carmela!, by José Sanchis Sinisterra; and Los niños perdidos, by Laila Ripoll. The liminal spaces created in these dramas -tombs, cemeteries, abandoned places, stages- allow the ghosts of memory to be embodied in the scene. The audience is thus impelled to look into the past and to reassess collective identity through the duty to remember.

Key Words: Memory. Contemporary historical drama. Liminality. Space. Ghosts.

\section{INTRODUCCIÓN}

Desde la Transición hasta la actualidad, el drama histórico en España ha recibido una especial atención por parte de la crítica teatral dada la gran cantidad de textos y de puestas en escena que se han producido $\mathrm{y}$, muy especialmente, por haberse constituido en "uno de los cauces preferidos por gran parte de los más relevantes autores dramáticos españoles para hacer llegar sus reflexiones sobre el acontecer sociopolítico y los grandes problemas universales" (Vilches de Frutos, 1999: 73) 2 . Coincidiendo con el final de la dictadura, la eliminación de la censura y la culminación de la transición política hacia la democracia, la escena comienza a revelar nuevas formas de entender la Historia y sus procesos. La representación de personajes y episodios históricos con la intención de trazar paralelismos más o menos velados con la realidad social del momento que caracterizó al drama histórico realizado bajo la dictadura franquista (Ruiz Ramón, 1978; Halsey, 1998; Rodríguez Richart, 2012), fue cediendo paso al protagonismo de personajes anónimos e historias familiares que apelan a la memoria colectiva del público y entroncan con el concepto unamuniano de la intrahistoria. En muchos casos, además, se

2. La bibliografía sobre el drama histórico producido en España en las últimas décadas es demasiado basta para recogerla en un trabajo de estas características. Cabe señalar, por la conjunción de esfuerzos colectivos desplegados, los volúmenes editados por Spang (1998), Romera Castillo y Gutiérrez Carbajo (1999), Romera Castillo (2003) y Floeck, Fritz y García Martínez (2008). Entre las monografías se hallan las de Habegger (1989), Hüttmann (2001), Ogando (2004) y García-Manso (2013). 
trata de dramas que proponen nuevas miradas sobre el pasado reciente, alumbrando acontecimientos, realidades y personajes marginados del discurso historiográfico y contribuyendo a generar interés sobre episodios y realidades poco conocidas ${ }^{3}$.

Dado que el drama histórico, entendido como subgénero, se atiene a una delimitación basada en criterios más temáticos que formales -pues, como es sabido, puede adoptar diversos registros, desde la farsa hasta el melodrama, e incluso combinarse con temáticas procedentes de otras tradiciones dramáticas, como la mitológica (Berninger, 2006: 24), las investigaciones han prestado una mayor atención a los temas y los enfoques adoptados en torno a la historia y la memoria dentro de un contexto sociopolítico concreto, en detrimento de una sistematización del corpus de carácter formal. En este ensayo, propongo llamar la atención sobre una especificidad formal que se halla estrechamente relacionada con las modalidades que el drama histórico adopta en nuestros días: la creación de espacios liminales como medio para vincular presente y pasado en la escena. Este fenómeno, que describiré y ejemplificaré a través del análisis de una selección de propuestas dramáticas de reconocidos autores y autoras españoles de los siglos XX y XXI, se puede observar también en el teatro histórico contemporáneo producido en otros países, constituyéndose por lo tanto en una característica del género en su expresión actual.

\section{LIMINALIDAD Y TEATRO}

El concepto de liminalidad (del latín lîmen, "límite", “umbral") fue introducido a principios del siglo XX por Arnold van Gennep en sus estudios antropológicos sobre los rites de passage, descritos como ritos que celebran el paso de un individuo de una posición bien definida a otra, como, por ejemplo, los relativos al nacimiento, la entrada en la vida adulta o el matrimonio ${ }^{4}$. Van Gennep ([1909] 1960: 10-11) señalaba que dichos

3. Así ocurre, por ejemplo, con las numerosas propuestas dramáticas en las que se rescatan las vidas de las mujeres de la II República y el exilio (García-Pascual, 2014), una tendencia creativa que se hace eco de los avances de los Estudios de las Mujeres y los Estudios de Género en el reconocimiento del papel de éstas en la Historia.

4. "Transitions from group to group and from one social situation to the next are looked on as implicit in the very fact of existence, so that a man's life comes to be made up of a succession of stages with similar ends and beginnings: birth, social puberty, marriage, fatherhood, advancement to a higher class, occupational specialization, and death. For every one of these events there are ceremonies whose essential purpose is to enable the individual to pass from one defined position to another which is equally well defined" (Gennep, [1909] 
rituales podían dividirse en tres subcategorías o fases: ritos de separación o preliminales, ritos de transición o liminales y ritos de incorporación o postliminales. En función de la finalidad que tenga el ritual en cuestión, un tipo de rito predomina sobre los otros. Victor Turner ([1969] 2008: 95) retomó décadas después el trabajo de van Gennep para analizar con mayor detenimiento el periodo liminal o umbral, en el que el individuo se halla en un momento de transición y ambigüedad entre distintas fases, de manera que su condición elude la clasificación que normalmente se les aplica a los estados y posiciones del espacio cultural:

Liminal entities are neither here or there; they are betwixt and between the positions assigned and arrayed by law, custom, convention, and ceremonial. As such, their ambiguous and indeterminate attributes are expressed by a rich variety of symbols in the many societies that ritualize social and cultural transitions. Thus, liminality is frequently likened to death, to being in the womb, to invisibility, to darkness, to bisexuality, to the wilderness, and to an eclipse of the sun or moon (Turner, [1969] 2008: 95).

Lo liminal aparece asociado, por lo tanto, a un estado de indefinición o ambigüedad identitaria. Después de producirse la transición de un estado a otro, la identidad del individuo queda redefinida y su nueva posición o estatus es reconocida por la comunidad y por el propio sujeto. Tras el desarrollo del concepto de la liminalidad y su aplicación al estudio de ciertas culturas tribales, Turner (1982: 41) destacó en trabajos posteriores el carácter liminal del teatro, al que prefería referirse como "liminoide", teniendo en cuenta las diferencias cruciales en su estructura, función, estilo, alcance y simbología, que lo distancian de los rituales de las sociedades tribales y agrarias. Según Turner (40), son liminoides las formas artísticas complejas y experimentales en las que se critica el status quo de la sociedad, mientras que las formas que refuerzan y legitiman la moral prevalente se aproximan más a la liminalidad practicada en los rituales y mitos tribales, en los que el orden establecido se subvierte con el fin de regresar, al final del proceso ritual, a la normalidad, recordando así a la comunidad cuáles 
son los beneficios de vivir fuera del caos. Posteriormente, Erika FischerLichte ([1990] 2002: 4) adoptó también la noción de la liminalidad para su estudio del teatro y la performance, con el fin de llamar la atención sobre la capacidad de este género para formar y transformar identidades: mientras que en los ritos de transición descritos en los estudios antropológicos son los actores los que sufren la transformación identitaria, en el teatro es el público el que queda expuesto a la posibilidad de cambiar su identidad, por lo que el teatro puede verse como espacio liminal en la medida en que es un lugar propicio para poner en jaque ideas, imágenes y convenciones.

A continuación, quisiera explorar y proponer una posibilidad más de la liminalidad, que parte de la conceptualización de ciertos espacios dramáticos como espacios liminales, en cuanto a que estos pueden constituirse en símbolo de la transición entre dos mundos o estados diferenciados. Así como el ser humano ha creado ritos que simbolizan el paso de un estado a otro - de la infancia a la madurez, de la soltería al matrimonio, etc.-, también existen lugares a los que otorgamos esa connotación de liminalidad, de espacio intermedio que transgrede la demarcación de unos límites y se adentra en el territorio de la ambigüedad. De hecho, a van Gennep ([1909] 1960: 15, 18-20) le interesaba el componente "mágico-religioso" del cruce de fronteras imaginarias -por ejemplo, el uso de una puerta, un umbral o un palio para simbolizar ese cambio de estado en algunos ritos y en ceremonias religiosas-. Igualmente, en el teatro es posible recrear espacialmente entornos en los que se sugiere la posibilidad de traspasar fronteras intangibles como las que dividen los binomios vida/muerte, sueño/vigilia, cordura/locura, etc. Se trata de un tipo de espacio en el que el personaje queda suspendido en una especie de tierra de nadie o en un estado de incertidumbre, que le permite ahondar en su propia historia y su pasado y llevar a cabo un proceso de anagnórisis.

En el caso del drama histórico contemporáneo, los espacios liminales responden a la tentativa de llevar a la materialidad de la escena discursos mnemónicos con los que se entrelazan temporalidades del presente y del pasado. Estos discursos no solo se transmiten a través de la palabra y el diálogo, sino que también se evidencian en la construcción de los personajes,

5. "Whilst in rites of transition it is generally the 'actors' who are to be transformed, in theatre, it is principally the spectators who are exposed to the possibility of a change in identity of role figures which they in fact only bring forth through performative acts. [...] In this sense, theatre can be described as a liminal space" (Fischer-Lichte, [1990] 2002: 4). 
la creación del espacio y el tiempo dramáticos. Así pues, los espacios liminales, fronterizos, permiten integrar figuras fantasmales y espectrales ${ }^{6}$, con las que se sitúa a los vivos - personajes y público espectador- ante un pasado que cobra vida en la escena. Además, los espectros en el teatro suelen contribuir a desencadenar el proceso de anagnórisis en los protagonistas, con el que se pretende involucrar al público en el trabajo de memoria. Como seres procedentes del más allá, del recuerdo o de la alucinación de otros personajes, se convierten en emisarios de la memoria, que vuelven para recordarles a los vivos la necesidad de seguir replanteándose el pasado (García-Manso, 2014: 88-90).

Los espacios liminales pueden generarse tanto mediante la escenografía, como mediante la iluminación, el espacio sonoro o el espacio lúdico y verbal, creado por los diálogos y los movimientos de los personajes. Por ejemplo, como espacios físicos y escenográficos destacan los lugares marcados por alguna tragedia del pasado o los lugares culturalmente asociados a lo liminal, como podría ser el caso de un cementerio o de unas ruinas históricas. A través del espacio verbal y lúdico, se pueden formar espacios liminales a través de personajes que entran en estados de trance y transmutación -como ocurre en Santa Perpetua, de Laila Ripoll, cada vez que la protagonista, una anciana vidente, entra en trance o es poseída por un espíritu-, o de personajes que están enfermos o a punto de morir, de manera que se hace posible el encuentro y la confusión entre sueño y vigilia -así ocurre en La paz del crepúsculo, de Itziar Pascual, cuando el protagonista enfermo cree charlar con el fantasma de Clark Gable-.

\subsection{La tumba de Antígona (1967) [24-07-1984], de María Zambrano}

Entre los lugares liminales por excelencia se hallan las tumbas y los cementerios, espacios dedicados a la rememoración y la conmemoración del pasado, que se prestan a la negociación identitaria del visitante ${ }^{7}$.

6. Véanse los estudios de Derrida (1993) y Gordon (2008) y, en relación con la literatura española las contribuciones del volumen editado por Resina (2000) y el estudio de Colmeiro (2011).

7. Este ensayo es deudor de un estudio de John P. Gabrielle (2006) en el que se refiere al cementerio como lugar liminal en Père Lachaise, de Itziar Pascual. Tal y como Gabrielle menciona en dicho trabajo, "cemeteries, as liminal places where geography and chronology are reshaped and history is spatially spread out, are diverse and relatively unexplored sites for examining the processes involved in the contemporary reconstitution of memory of self, family and group, in place and trans-spatially" (Francis, Kellaher y Neophytou, 2005: 180). 
Son varios los ejemplos de dramas históricos que en las últimas décadas han optado por este tipo de ambientación, como ocurre en La tumba de Antígona (México, 1967), de María Zambrano, un drama que ha servido de inspiración para otras creaciones escénicas que podrían analizarse aquí -por ejemplo, Juana-delirio (2005), de Eva Hibernia, obra protagonizada por Juana de Arco, la Doncella de Orleans, que rinde homenaje al drama de la filósofa malagueña (García-Manso, 2013: 305)-. Zambrano escribió este texto dramático en el exilio $\mathrm{y}$, aunque la primera edición -que vio la luz en México- data de 1967, habría que esperar hasta 1983 para su publicación en España ${ }^{8}$.

La universalidad del mito, entendido éste como modelo y ejemplo de la historia, ha permitido entender esta obra en su contexto de recepción como una alegoría sobre la tragedia española de la Guerra Civil y la dictadura, que cercenó y ocultó la voz de una parte de la comunidad, defensora de la libertad y la democracia (Vilches de Frutos, 2006) ${ }^{9}$. Dicha alegoría puede rastrearse asimismo en el proceso creativo. Como es sabido, Antígona fue un personaje fundamental en el pensamiento de la filósofa malagueña en su etapa del exilio, a la que dedicó numerosas páginas (Bundgård, 2000; Pino Campos, 2005; Plaza Agudo, 2009; Trueba Mira, 2012). La indagación que Antígona realiza en su propia historia y la de su familia, se convierte, en este sentido, en una indagación en la memoria y la identidad colectiva, como Zambrano (1996: 103) advierte en "Delirio de Antígona", ensayo publicado en 1948: "No podemos dejar de oírla, porque la tumba de Antígona es nuestra propia conciencia obscurecida. Antígona está enterrada viva en nosotros, en cada uno de nosotros". A lo largo de las doce escenas que componen la obra, cuyos títulos informan sobre el contenido o los personajes implicados en las mismas, Antígona examina

8. La primera puesta en escena íntegra tuvo lugar el 24 de julio de 1984 en el Teatro Lope de Vega de Vélez-Málaga bajo la dirección de Juan Hurtado (Nieva de la Paz, 1999: 296-297). El 13 de agosto de 1992 se produce un emblemático estreno en el escenario del Teatro Romano de Mérida, en versión preparada y dirigida por Alfredo Castellón. Para el análisis que sigue tomo como referencia la edición crítica preparada por Virginia Trueba Mira (2012), en la que la investigadora recoge en notas a pie de página las variaciones observables en borradores y versiones manuscritas desechadas por Zambrano, entre las que destaca - por lo que se refiere a la comprensión del texto espectacular- la supresión de la práctica totalidad de las acotaciones escénicas en la versión final del texto dramático, con la excepción de una, contenida en la escena titulada "Sueño de la hermana" (Zambrano, 2012: 182).

9. El drama mitológico se emparenta a menudo con el drama histórico debido a que se sirve de mecanismos similares para trazar paralelismos entre pasado y presente. En algunos casos, además, se actualizan los arquetipos y temas míticos con el fin de reflexionar sobre hechos históricos concretos (Vilches de Frutos, 1983: 184, 207; Nieva de la Paz, 1997: 123-124; Ragué-Arias, 2005; Romera Castillo, 2008: 130). 
su vida pasada, su experiencia del exilio como portadora de conocimiento y perpetuadora de la memoria; de la guerra fratricida que enfrentó a sus hermanos; de su defensa del deber moral de enterrar a los muertos por encima de la injusticia manifiesta de la orden del tirano Creón de prohibir que se le diera una sepultura digna a su hermano Polinices; y de su decisión de acatar, hasta sus últimas consecuencias, la condena a ser desterrada tanto del mundo de los vivos como del de los muertos.

El drama transcurre en el espacio cerrado de la tumba de Antígona, un entorno simbólico y liminal, que "representa a la vez el espacio del exilio, del tránsito hacia la muerte, y el de la revelación" (Azcue, 2009: 38). Dicho "espacio intermedio" (Trueba Mira, 2012: 103) le permite a Antígona vivir esa revelación, ese reconocimiento de su propia identidad, gracias a la confrontación con su memoria y sus fantasmas: su hermana Ismene, sus hermanos Etéocles y Polinices, el rey Creón, su prometido Hemón... Como señala Pilar Nieva de la Paz (1999: 290), "estos sucesivos encuentros con sus fantasmas familiares, consigo misma a través de su relación pasada con los otros, conducen paulatinamente a Antígona hacia lo más profundo de sí misma, hacia las grandes preguntas de la razón última, en un proceso de progresiva purificación". Así pues, la anagnórisis de la protagonista se produce a través del diálogo con su memoria y sus propios fantasmas, con quienes se reencuentra en el espacio liminal de la tumba, donde ella se enfrenta conscientemente a su pasado y a la Historia, motivo por el cual la protagonista afirma que no podrá salir de allí (morir) hasta que sea capaz de tejer la tela de su memoria: "Me dejas sola con mi memoria, como la araña. A ella le sirve para hacer su tela. Esta tumba es mi telar. No saldré de ella, no se me abrirá hasta que yo acabe, hasta que yo haya acabado mi tela" (Zambrano, 2012: 195-196). La necesidad de rememorar hasta alcanzar un conocimiento de la verdad es lo que la mantiene con vida dentro de su tumba: "Por eso no me muero, no me puedo morir hasta que no se me dé la razón de esta sangre y se vaya la historia, dejando vivir a la vida" (186).

La protagonista del drama se halla, por tanto, en un momento de su vida que es en sí mismo liminal: el paso hacia la muerte, una transición que le aporta la lucidez necesaria para repasar su vida en lo que Zambrano llama en su Prólogo el "delirio" de Antígona: "Mientras la historia que devoró a la muchacha Antígona prosiga, esa historia que pide sacrificio, Antígona seguirá delirando" (Zambrano, 2012: 173). Para acometer el proceso de 
anagnórisis, la protagonista precisa de la ayuda de sombras, fantasmas o seres del más allá y visitantes que le permiten entrar en diálogo con su pasado $^{10}$. Los títulos de algunas escenas apuntan ya al carácter espectral de estas presencias que pueden manifestarse o no en la escena, como sucede con los dos monólogos en los que Antígona se dirige respectivamente a su hermana Ismene, titulado "Sueño de la hermana", o a su madre Yocasta, titulado "La sombra de la madre". Lo espectral se pone de manifiesto en estos casos por la intangibilidad de los personajes; al ser caracterizados como sombra o como sueño, su representación física no es necesaria en la escena, puesto que su ausencia se puede suplir mediante una interpretación adecuada del "delirio" de la protagonista" ${ }^{11}$. En otros casos, como ocurre con las figuras de Edipo, la nodriza Ana, la Harpía - personaje alegórico-, los hermanos Etéocles y Polinices o Hemón, lo espectral toma cuerpo a través de la interpretación actoral y la protagonista entabla un diálogo directo con estos seres venidos del más allá o de un espacio mítico.

Así pues, el espacio liminal elegido por la autora en este drama, un espacio que por su significado cultural -la tumba como lugar de reposo de la muerte- como por el valor simbólico que adopta en el drama -el lugar en el que Antígona es encerrada para morir en vida- tiene la función de crear un ambiente adecuado para que se produzca el proceso de indagación identitaria de la protagonista mitológica, un proceso que tiene lugar con la aparición de los fantasmas de su memoria, y que culmina con la anagnórisis de su pasado y con una apelación final al público. Dicha apelación se produce a través de los Desconocidos, dos personajes misteriosos ${ }^{12}$ que se aproximan a Antígona con diferentes propósitos, pero que coinciden en

10. Es habitual en las producciones culturales presentar a los fantasmas como un desdoblamiento del Yo o de la propia conciencia. Las obras dramáticas que analizo aquí dan buena cuenta de esta figuración dramática del fantasma con la finalidad de indagar en la identidad, sea individual o colectiva. Véase también García-Manso (2014).

11. No obstante, la posibilidad de representar a estos personajes con intérpretes en la escena permanece abierta al criterio de la dirección. Por ejemplo, en "La sombra de la madre", Antígona alude en su monólogo a la presencia acechante de una sombra junto a ella: “Ay, eres tú, Madre, vuelves. Vuelves aquí también. No has encontrado reposo" (Zambrano, 2012: 197). En nota a pie de página, Trueba Mira recoge la siguiente acotación de Zambrano, que fue eliminada por la autora en la edición final del drama: "La madre será una sombra grande, densa, oscura, que no habla. Cifra de la fatalidad, suplicante a veces" (Zambrano, 2012: 197, n. 55).

12. Nuevamente, la comparación del texto dramático con las versiones previas del mismo recogidas por Trueba Mira, arroja luz sobre la construcción de estos dos personajes que no carecen -en su versión final-de cierta mistificación: el Desconocido Primero es un hombre, no es "de aquellos que se filtran por las paredes" (Zambrano, 2012: 233), mientras que el Desconocido Segundo no es "un simple hombre como los demás" y parece "una aparición, una figura de esos sueños que luego nos acompañan" (233). 
valorar su palabra. La escena final, en este sentido, resulta fundamental en el drama, puesto que en ella se traslada el testigo de la memoria al público, produciéndose el "mandato de la memoria":

DESCONOCIDO SEGUNDO: [...] Mas nunca se irá, nunca se os irá del todo.

DESCONOCIDO PRIMERO: Hablas por enigmas. ¿Quieres decir que va a seguir aquí sola, hablando en alta voz, muerta hablando a viva voz para que todos la oigamos? ¿Es que va a tener vida, y voz?

DESCONOCIDO SEGUNDO: Si; vida y voz tendrá mientras siga la historia.

DESCONOCIDO PRIMERO: Mientras haya hombres. DESCONOCIDO SEGUNDO: Mientras haya hombres hablará sin descanso, como la ves ahora, en el confín de la vida con la muerte. ¿Has entendido?

DESCONOCIDO PRIMERO: Sí, no; no del todo. Vendré aquí, me acercaré por la noche para recoger su palabra en el silencio.

DESCONOCIDO SEGUNDO: No es eso; no será así. La oirás más claramente de lejos, aunque estés sumergido en otros asuntos. Pues que tú la oirás el primero. Y esas palabras que se aglomeran ahora en tu garganta, saldrán sin que lo notes. Su voz desatará tu lengua (Zambrano, 2012: 235-236).

El uso de una apelación en la primera intervención del Desconocido Segundo en este fragmento - "nunca se os irá del todo"- y de la primera persona del plural en la réplica del Desconocido Primero - "para que todos la oigamos"- permiten involucrar al público en ese mensaje final del drama, que se presta a diversas interpretaciones: desde el carácter atemporal del mito y la tragedia de Antígona, hasta su valor específico en la versión y actualización propuesta por María Zambrano, vinculada con su experiencia de la Guerra Civil y del exilio. 


\subsection{Bleiche Mutter, zarte Schwester o Le retour de Carola Neher [14-07-1995] (1998), de Jorge Semprún}

Otro ejemplo de recreación de un cementerio como espacio liminal se encuentra en Bleiche Mutter, zarte Schwester ("Lívida madre, tierna hermana"), obra dramática de Jorge Semprún. La peculiaridad de este drama reside en que fue escrito por encargo del director de escena Klaus Michael Grüber para ser representado -literalmente- en un cementerio: el cementerio soviético del parque Belvedere, situado en las inmediaciones de la ciudad de Weimar, en Alemania. Semprún redactó el drama originariamente en francés ${ }^{13}$, con la instrucción de Grüber de que tenía que tratar sobre la historia reciente alemana. El lugar de la puesta en escena ${ }^{14}$, en el que sucede la acción dramática, tenía un significado especial para Semprún, pues se halla a tan solo 15 kilómetros del Ettersberg, colina y bosque en el que fue construido el campo de concentración de Buchenwald donde estuvo recluido durante casi 15 meses $^{15}$, tras ser detenido en Francia por la Gestapo (Nieto, 2014: 30-32). Además, dicho cementerio cuenta con un valor simbólico añadido como escenario, dado que su historia está marcada por los dos totalitarismos del siglo XX: el nazismo y el estalinismo. Fundado en 1938 como cementerio para el descanso de los combatientes de mayor edad -su impulsor, Fritz Sauckel, jefe del distrito (Gauleiter) de Turingia durante el gobierno nacionalsocialista, quiso enterrar allí a su padre, quien había luchado en la I Guerra Mundial-, fue desprovisto de la simbología nazi y reconvertido en cementerio soviético en 1946 con la ocupación de la Alemania del Este (Manger, 1999: 337).

El protagonista del drama es el Superviviente, alter ego de Jorge

13. La versión alemana fue traducida por Hanns Zischler. Sigo para las citas la edición en francés, publicada y estrenada en el país galo con el título de Le retour de Carola Neher (1998), en el que se alude a uno de los personajes centrales del drama. Neher fue una actriz alemana que actuó en obras de Brecht y que fue doble víctima del nazismo y del estalinismo, tras abandonar Alemania en 1933 por su oposición a Hitler y, posteriormente, cuando residía en Moscú, ser acusada de trotskista y encerrada en un gulag, en el que falleció en 1942. En un discurso de 1995 titulado "Una mirada al futuro de Alemania", Semprún afirmó que "el recuerdo de Carola Neher; la evocación de su trágico destino -víctima como lo fue de los dos totalitarismos que han asolado a Europa en este siglo- conducen irremediablemente a una reflexión sobre Alemania" (Semprún, 2006: 173).

14. Tuvo lugar el 14 de julio de 1995 en el marco del Kunstfest Weimar.

15. Jorge Semprún fue deportado el 27 de enero de 1944 desde Compiègne y llega a la estación del campo de concentración la noche del 29 de enero (Nieto, 2014: 34). La liberación de Buchenwald se produce el 11 de abril de 1945 (48). 
Semprún, cuyos recuerdos del pasado y obsesiones toman cuerpo en la escena a través de personajes espectrales, anacrónicos, que en el presente en el que transcurre la acción dramática están muertos. El Superviviente convoca a sus fantasmas de la memoria porque sabe que va a morir, tal y como indica en la escena 11: "c'est mon dernier jour... Il me faut convoquer tous mes fantômes!" (Semprún, 1998: 35). Al igual que la Antígona del drama de Zambrano, el Superviviente se halla en un momento liminal: el tránsito de la vida a la muerte. Por ello, regresa a las inmediaciones del campo de concentración de Buchenwald, el lugar que marcó su vida -su condición de superviviente, que es la que le da razón de ser en la obra ${ }^{16}$, para morir tranquilo. Allí se reencuentra con sus fantasmas en lo que define como un sueño: “j'ai fui... Je suis revenu dans les parages de l'Ettersberg, pour y mourir tranquille... J'y ai retrouvé en rêve des fantômes de mon passé..." $(55)^{17}$.

¿Quiénes son, entonces, los fantasmas del Superviente? Jorge Semprún introduce en este drama a una serie de personajes reincidentes de su obra, que se hallan muy presentes también en su narrativa testimonial y en su producción ensayística. En conjunto, conforman un elenco de personajes -varios de ellos históricos- aparentemente dispares y procedentes de diferentes épocas. Por un lado, están Johann Wolfgang von Goethe (1749-1832) y Corona Schröter (1751-1802), quien interpretó por primera vez el papel principal de la Ifigenia en Táuride, obra del gran autor del romanticismo alemán que fue protagonista de la época dorada de la cultura en Weimar, en cuyas inmediaciones tiene lugar la obra. También está Léon Blum (1872-1950), político francés que fue deportado en un edificio especial para personalidades cerca de Buchenwald. Blum fue, además, autor de las Nouvelles conversations de Goethe avec Eckermann (1901), motivo por el cual Semprún se permite imaginar en la obra un diálogo entre Goethe y Blum. Por su parte, el grupo de personajes llamados Musulmanes y el propio Superviviente proceden de la intrahistoria del campo de concentración. En la jerga de los campos, los "musulmanes" (Muselmänner) eran aquellas personas que se encontraban más allá de la vida, que habían perdido toda esperanza de supervivencia. Todos estos

16. Jorge Semprún afirmó que se identificaba "por encima de todo" como "ex deportado de Buchenwald", como su alter ego escénico (Semprún, 2006: 174).

17. El Superviviente huye, entre otras cosas, porque no soporta la idea de ser el último testigo vivo. Esta idea aparece ya en Se taire est imposible (1995), de Elie Wiesel y Jorge Semprún (Céspedes, 2015: 172). 
personajes están, de una u otra manera, ligados al Ettersberg. El personaje de Carola Neher, por su parte, representante de las víctimas de los dos totalitarismos, se convierte metateatralmente en Corona Schröter cuando interpreta fragmentos de la Ifigenia de Goethe y se identifica con ella. Un último personaje, el Joven Musulmán, que es en realidad un refugiado de la guerra de Bosnia, con el que se cierra el ciclo de los tiempos superpuestos en la obra, es conminado -junto con el público asistente o lector- a acatar el deber de la memoria, cuando, tras preguntarle al Superviviente qué puede hacer por él, éste le contesta: "Recordar" (Semprún, 1998: 55). Con esta escena se revela, como ocurre con asiduidad en el drama histórico contemporáneo, el mandato de memoria que estas obras quieren trasladar al público.

\section{3. ¡Ay, Carmela! [5-11-1987] (1989), de José Sanchis Sinisterra}

¡Ay, Carmela! Elegía de una guerra civil en dos actos y un epílogo, el conocido drama de José Sanchis Sinisterra ${ }^{18}$, encaja también en una concepción liminal del espacio dramático, si bien por motivos diferentes a las obras referidas anteriormente, puesto que, en este caso, no se trata de un lugar culturalmente asociado a la frontera entre la vida y la muerte, como son la tumba o el cementerio, sino a un lugar en el que las fronteras entre realidad y ficción se diluyen y, como en cierto momento expresa el protagonista del drama, "todo vale" (Sanchis Sinisterra, 1991: 224): el escenario de un teatro. Al valor polisémico de todo escenario se le añade aquí su identificación como lugar de memoria, en el sentido defendido por Pierre Nora, pues, como se indica en los diálogos de los personajes, se trata del escenario del Teatro Goya de Belchite, pueblo cuyas ruinas fueron preservadas tras el final de la Guerra Civil por deseo del dictador Francisco Franco. Por otra parte, a lo largo de la acción se hace patente que se trata de un lugar abandonado, en el que un ebrio, confuso y solitario Paulino asiste a la repetición de la trágica ejecución de su compañera Carmela.

La acotación inicial del texto indica que "la acción no ocurrió en Belchite en marzo de 1938" (Sanchis Sinisterra, 1991: 187). Según parece indicar el autor en el programa de mano del estreno, recogido en

18. Fue estrenado el 5 de noviembre de 1987 en el Teatro Principal de Zaragoza bajo la dirección de José Luis Gómez. La primera edición de la obra fue publicada por la revista El Público en 1989. Sigo aquí la edición preparada por Manuel Aznar Soler para la editorial Cátedra en 1991. 
el apéndice de la edición del texto dramático preparada por Manuel Aznar Soler, esta curiosa declaración se debe al hecho de que la acción dramática es "totalmente ficticia, en soporte y perspectiva imaginaria de la tragedia colectiva" (296). No obstante, dadas las connotaciones maravillosas del encuentro post mortem de Carmela y Paulino, también es posible interpretar que la enunciación negativa de la acotación sugiere todo aquello que tiene el drama de irreal y fantástico, de imposible: hacer regresar a los muertos para poner en tela de juicio la desmemoria de los vivos. El estreno de la obra se produce, de hecho, en 1987, tan solo un año después de que se cumplieran 50 años del comienzo de la Guerra Civil, una conmemoración que no tuvo lugar de manera oficial en España ${ }^{19}$ y que hace especialmente significativa la introducción del "mandato de memoria" que pronuncia el personaje de Carmela en el Epílogo.

Tanto el primer acto como el segundo comienzan de igual manera: con un "escenario vacio, sumido en la oscuridad" (Sanchis Sinisterra, 1991: 189), en el que, tras encenderse una luz de ensayos, entra un Paulino "vacilante", vestido de manera descuidada y con una garrafa de vino, que mira hacia el escenario, bebe y sale corriendo a orinar. En el comienzo del Primer Acto, la garrafa de vino que lleva consigo y su lamentable actitud-lo mismo entona un pedazo de la canción republicana de la Guerra Civil, “¡Ay, Carmela!", como recita unos versos del romance falangista de Federico de Urrutia "Castilla en armas" o "hace sonar [...] varias ventosidades que evocan un toque de trompeta" (190)-, nos hacen pensar en que está ebrio. El estado de embriaguez podría hacerle confundir la realidad hasta el punto de imaginar los encuentros extemporales con Carmela, pero, durante su primer encuentro, ella explica que su aparición "no es por el vino" y declara que está ahí "de verdad" $(192)^{20}$. En el segundo encuentro, al final del Primer Acto, Paulino vuelve a insistir en lo increíble de la situación: "yo no sé lo que es esto. [...] Lo que nos pasa... Que tú estés aquí, muerta, y que podamos hablar, tocarnos... No entiendo cómo está ocurriendo, ni por

19. Bernecker (2009: 25-27) ofrece varias explicaciones a la decisión del gobierno del PSOE de no realizar una conmemoración oficial del cincuentenario de la Guerra Civil: la coyuntura política -iban a celebrarse elecciones parlamentarias en junio de 1986-, el deseo de reconciliación y el temor de reabrir viejas heridas y poner en peligro la estabilidad política de la democracia.

20. El drama presenta de forma ambigua la condición del personaje de Carmela. Virtudes Serrano cuestiona: "con la presencia de Carmela en escena, el tiempo se diluye y el público queda al límite de lo verosímil. ¿Se halla ante el espectro errante de la pobre cómica asesinada que ha conseguido materializarse o asiste a un ejercicio de participación en las ocultas "galerías del alma" de Paulino, que escapa de la soledad por la rememoración?" (1998: 75). 
qué...” (217) y aducirá las posibles explicaciones racionales, para después rechazarlas: "Te juro que casi no he bebido... Y soñar, ya sabes que yo no sueño nunca... o casi" (218). Más interesantes, en lo que respecta a la delimitación del espacio liminal, son sus reflexiones al comienzo del segundo acto, cuando vuelve a cuestionarse las apariciones de Carmela y las achaca al hecho de encontrarse en un teatro vacío, un espacio en el que, aparentemente, todo es posible, controlado por un "vago e invisible" demiurgo al que se dirige con insistencia en busca de respuestas:

PAULINO: Esto no es natural... Esto es demasiada casualidad... Esto ya es adrede... Aqui pasa algo que... Aqui hay alguien que... Porque yo no estoy borracho. $Y$ es entrar aqui $y$, dale que te pego: todo son cosas raras... Aquella que aparece como si nada, la noche de marras que vuelve, las luces que se disparan solas... y ahora, la gramola, haciéndome trucos de feria... ;Vamos, hombre! Un poco de formalidad... (A un vago e invisible interlocutor.) ¿Qué pasa? ¿Que, porque esto sea un teatro vacio, ya todo vale? ¿Cualquier ocurrencia, iplum!, ya está? ;Vamos, hombre!... Buenas están las cosas por ahi afuera para andar con fantasias... [...] Y si vuelvo de vez en cuando a este teatro, no es para que nadie juegue conmigo a hacer magia barata, ni a los fantasmas, ni a ... (Brusca transición. Grita, casi implorante.) ¡Carmela! ;Ven, Carmela! ¡Como sea, pero ven! iDe truco, o de mentira, o de teatro...! ;Me da igual! ¡Ven, Carmela!... (Sanchis Sinisterra, 1991: 224).

El espacio dramático, esta vez constituido por un escenario teatral "vacío", se convierte en lugar liminal en la medida en que las fronteras entre fantasía y realidad -entiéndase por realidad, la recreada en el mundo ficcional del drama- se diluyen ${ }^{21}$. Los personajes del drama asumen que el escenario es el lugar de la representación y la posibilidad, es decir, el lugar en el que todo es susceptible de tomar cuerpo a través de la imitación

21. Así lo dan a entender los dos personajes en otro momento de la acción: "PAULINO: [...] (Mira el escenario y la sala.) Es curioso... / CARMELA: ¿Qué? / PAULINO: Esto... Este sitio... Un teatro vacío. / CARMELA: ¿Por qué? / PAULINO: La de cosas que... / CARMELA: (Mira el escenario y la sala.) Sí, la de cosas... / (Quedan los dos mirando, en silencio.)" (Sanchis Sinisterra, 1991: 212-213). 
y la sustitución. Los cambios en la iluminación, junto con los cambios en el vestuario de Carmela, anuncian saltos en los tiempos evocados y en la alternancia de lo real -encarnado por un solitario Paulino-y lo maravilloso -que se hace explícito con las apariciones de Carmela en escena-. Las entradas de Carmela muerta se anunciarán siempre con la proyección de una luz blanquecina por un lateral del fondo, "como si se hubiera abierto una puerta" (Sanchis Sinisterra 1991: 192), mientras que las entradas de la Carmela que anuncia el regreso al día de la actuación fatal se sugieren con una iluminación brillante y brusca. Por ejemplo, al final del primer acto, cuando Paulino intenta seguir a Carmela, que regresa al mundo de los muertos, "sale tras ella, pero al punto vuelve a entrar, como impulsado por una fuerza violenta que le hace caer al suelo. La luz blanquecina se apaga" (221). Por su parte, al comienzo del segundo acto, cuando Paulino clama por la reaparición de Carmela, como se puede leer en el fragmento reproducido más arriba, "la escena se ilumina bruscamente [...] y vuelve a sonar el mismo pasodoble: "Mi jaca". Pero esta vez, además, entra Carmela con su vestido andaluz y un gran abanico, desfilando y bailando garbosamente" (225). Estos cambios en las luces, el vestuario y la actitud de los personajes permiten diferenciar, por tanto, entre los momentos en los que el tiempo de la acción se sustenta en "la analepsis o el flashback" (Gutiérrez Carbajo 1999: 289) y el tiempo en el que lo irreal -la aparición del fantasma de Carmela- irrumpe en la escena.

Por último, en iAy, Carmela! se incluye también el mandato de memoria con el que se apela al público a no olvidar lo ocurrido. En el último acto, titulado "Epílogo", se produce un tercer encuentro entre un Paulino que ha optado por ponerse la camisa azul de la Falange, deseoso por agradar a las autoridades y garantizar su supervivencia, y una Carmela que cada vez se encuentra más "borrosa" y alejada del mundo de los vivos. Carmela le explica a Paulino que una compañera catalana ha propuesto hacer una especie de club o asociación de la memoria ${ }^{22}$, algo que ayude a "recordarlo todo", especialmente a los vivos, que todo lo olvidan:

$$
\text { PAULINO: Bueno, ¿y ese club? }
$$

22. La apelación al público, que se explicita en el uso de la segunda persona del plural en la última réplica del fragmento, cobra un mayor sentido si se tiene en cuenta lo señalado en la nota 19 y que en el momento en el que se estrena el drama todavía no existía la Asociación para la Recuperación de la Memoria Histórica, fundada en el año 2000 . 
CARMELA: O lo que sea, que ya se verá... Pues para hacer memoria.

PAULINO: ¿Qué quieres decir?

CARMELA. Sí: para contarnos lo que pasó, y por qué, y quién hizo eso, y qué dijo aquél...

PAULINO: ¿Y para qué?

CARMELA: Para recordarlo todo.

PAULINO: ¿A quién?

CARMELA: A nosotros... y a los que vayáis llegando...

PAULINO: (Tras una pausa.) Recordarlo todo...

CARMELA: Sí, guardarlo... Porque los vivos, en cuanto tenéis la panza llena y os ponéis corbata, lo olvidáis todo (Sanchis Sinisterra, 1991: 261).

\subsection{Los niños perdidos [15-10-2005] (2005), de Laila Ripoll}

El teatro español contemporáneo ha seguido ofreciendo numerosos ejemplos de espacios liminales en el drama histórico de años recientes. En Los niños perdidos (2005) [15-10-2005] $]^{23}$, de Laila Ripoll, la configuración del espacio liminal parte de la representación de un antiguo desván, un lugar destinado a almacenar aquellas cosas que ya no se usan, que no funcionan o que no se utilizan con frecuencia. Pero un desván es también un contenedor de recuerdos, un lugar en el que se puede hacer memoria a través de los objetos, liminal porque permite establecer una conexión entre presente y pasado. En Los niños perdidos, el desván es, además, un espacio marcado por la tragedia, aunque los detalles de la misma no se conocen con exactitud hasta el final del drama, cuando los niños protagonistas viven su particular anagnórisis y afrontan la verdad de su existencia. Toda la acción transcurre en el desván de un orfanato, descrito en la primera acotación a través de un decorado realista: un armario desvencijado, un sillón de dentista roto, un biombo con la tela rasgada e imágenes de santos a las que les falta un ojo o una mano... (Ripoll, 2010: 37). De manera similar

23. Fue estrenada por la compañía Micomicón, que dirige Laila Ripoll, el 15 de octubre de 2005 en el Centro Rigoberta Menchú, de Leganés, en el marco del X Festival Internacional Madrid Sur e incluida después en la programación del Centro Dramático Nacional. La obra cuenta con varias ediciones, la primera de ellas publicada en 2005. Sigo para las citas la edición prologada por Francisca Vilches de Frutos en la editorial KRK (2010). 
a como ocurre en $; A y$, Carmela!, dicha decoración invita a pensar en la decadencia del lugar, cuyo abandono comparten los niños -Cucachica, por ejemplo, señala varias veces haberse orinado por el miedo, y los otros niños le reprochan que huele mal-. Al inicio de la obra, tres niños se esconden allí de Sor Resurrección, una temible monja del orfanato por la que Tuso, un adulto con discapacidad intelectual, se hace pasar para jugar con sus amigos. La grotesca imitación de Tuso (Reck, 2012: 71) revela que aquella mujer, de la que huyen los niños, esconde un lado oscuro y cruel.

Si en el texto dramático de José Sanchis Sinisterra era la iluminación la que anunciaba la intromisión de lo sobrenatural y lo liminal en la escena, en la obra de Laila Ripoll es el espacio sonoro (Vilches de Frutos, 2010: 27-28) el que va dando a entender que las cosas no son lo que parecen, retrotrayendo a los niños y a los espectadores a momentos del pasado relacionados con la Guerra Civil y la posguerra y con las trágicas experiencias vividas en el orfanato, dada su condición de "niños perdidos", huérfanos, arrebatados a sus padres por pertenecer al bando de los vencidos o abandonados. La introducción de voces y sonidos procedentes de otra época permite a los personajes evocar "los suplicios [...] antes de llegar al orfanato" y escenificar "las huellas del trauma" (Souto, 2014: 55). Dicho trauma se refleja también en los juegos de los niños (Avilés Diz, 2016: 346), gracias a los cuales se le va revelando al público información sobre sus aciagos pasados: el hambre, la separación forzada de los padres, la exclusión atroz a la que se les ha sometido por ser hijos de "rojos", los castigos padecidos en el orfanato y el robo de su identidad.

Desde los primeros momentos del drama, el espacio del desván se erige como un lugar de encierro ${ }^{24}$, cuyo entorno opresivo los niños tratan de mitigar con juegos metateatrales, que suelen terminar en discusiones y en la evocación y re-presentación de malos recuerdos -el viaje en un tren de ganado, la vida en la calle durante la guerra, el rechazo de los vencedores, etc.-. Los juegos de los niños, reproducidos con un lenguaje que combina la ternura infantil con un humor negro y escatológico muy habitual en la obra de Ripoll, se ven, en consecuencia, interrumpidos por transiciones de gran dramatismo en las que se revelan sus historias y, en ocasiones, por episodios de verdadero pavor en los que se oye el "sonido de aviones",

24. "CUCA: Jo, yo me quiero ir de aquí. / LÁZARO: No podemos. Ya sabes que no podemos" (Ripoll, 2010: 74). 
explosiones y "voces, gritos, susurros espectrales, como venidos de otra dimensión" (Ripoll, 2010: 73), a modo de psicofonías que devuelven a los niños a momentos clave de su pasado, en los que estaban en peligro e indefensos.

Al final del drama, los niños logran reconstruir su pasado y se dan cuenta de que en realidad, todos ellos existen solamente en la memoria de Tuso, es decir, que son sus fantasmas. Cuando Tuso revela que los tres niños murieron tras el brutal castigo y paliza de sor Resurrección, y que esta fue empujada por las escaleras por él mismo, su proceso de anagnórisis y el de los niños llega al momento culminante y se produce el mandato de memoria, con el que se apela implícitamente al público a recordar el triste destino de tantos inocentes:

TUSO: Al final conseguí que subiera sor Irene y cuando os vio tiesos y llenos de sangre casi se vuelve loca. Decidieron no dar parte para no montar un escándalo. Total, ya erais niños perdidos. Al fin y al cabo, los niños de aquí no existen. Son como fantasmas y nadie va a reclamar por ellos. Mejor echar tierra encima, nunca mejor dicho (Ripoll, 2010: 114).

El desván abandonado se convierte, de esta manera, en un espacio liminal en el que vivos y muertos comparten juegos y lo real y lo fantástico se entremezclan, permitiendo que los fantasmas de Tuso se materialicen para contar su historia y apelar al público a no olvidar a las víctimas más desprotegidas de las guerras: los niños. Como señala Jo Labanyi (2000: 66), una de las formas de lidiar con los fantasmas del pasado consiste en asumir su presencia a través del trabajo de duelo, mediante el reconocimiento de la historia y la convivencia con sus huellas ${ }^{25}$. En consonancia con esto, los protagonistas de los dramas analizados -Tuso en Los niños perdidos, Paulino en iAy, Carmela!, el Superviviente en Le retour de Carola Neher y Antígona en La tumba de Antígona- se enfrentan a su propio pasado -un pasado de alcance colectivo-convirtiéndose en "la metáfora de un presente que para muchos exige la superación de un pasado aún traumático" (Amo Sánchez, 2008: 256). El público teatral es invitado a confrontar y exorcizar

25. "Or one can offer [the ghosts] habitation in order to acknowledge their presence, through the healing introjection process that is mourning [...]. This last option -accepting the past as past- is an acknowledgement of history, that allows one to live with its traces" (Labanyi, 2000: 65-66). 
a sus propios fantasmas y a transformar sus propios patrones identitarios.

\section{CONCLUSIÓN}

Los espacios liminales en el teatro se configuran a través de espacios dramáticos simbólicos o culturalmente asociados a lo liminal, que sitúan al personaje en un lugar intermedio, a medio camino y en la transición entre dos estados diferenciados, entre los que el protagonista se debate en un proceso de anagnórisis o de reconocimiento identitario. En el caso concreto del drama histórico contemporáneo, los lugares liminales permiten generar una intersección entre pasado y presente propicia para introducir discursos mnemónicos y llevar a los personajes -y al público, por extensión- a indagar en su propio pasado y en la construcción de la identidad colectiva. Estos espacios conllevan en las obras analizadas aquí la aparición de personajes espectrales o fantasmas que permiten dar cuerpo a la memoria en la escena, introduciendo nuevas dimensiones temporales en la acción dramática. Entre los espacios liminales recreados en el teatro histórico destacan las tumbas - La tumba de Antígona-y los cementerios -Bleiche Mutter, zarte Schwester / Le rétour de Carola Neher- como lugares de encuentro entre la vida y la muerte, el escenario teatral como espacio en el que lo real y lo fantástico puede confundirse-jAy, Carmela!-, los lugares abandonados y marcados por una tragedia del pasado -Los niños perdidos-, y, en definitiva, todos aquellos lugares susceptibles de convertirse en un puente de unión entre estados, tiempos y/o espacios culturalmente enfrentados.

En las cuatro obras dramáticas comentadas, todas ellas relacionadas con acontecimientos históricos concretos, la creación de un espacio liminal tiene la función de conectar presente y pasado en la escena mediante la aparición de fantasmas, muertos vivientes, sombras y seres venidos del más allá que permiten introducir discursos mnemónicos, con los que se conmina al público lector o espectador a tener en cuenta el mandato de memoria. Los espacios liminales sitúan al sujeto - tanto al protagonista teatral como al público, invitado a ponerse en su piel- ante una disyuntiva identitaria. El proceso de anagnórisis vivido por los personajes se convierte, así, en una invitación a que el público transforme su propia identidad. 


\section{REFERENCIAS BIBLIOGRÁFICAS}

AMO SÁNCHEZ, A. (2008). “Los niños perdidos, de Laila Ripoll: la memoria histórica al servicio de la identidad colectiva". En Dramaturgias femeninas en el teatro español contemporáneo: entre pasado y presente, W. Floeck, H. Fritz y A. García Martínez (eds.), 245-258. Hildesheim: Georg Olms.

AVILÉS DIZ, J. (2010). "La Trilogía de la memoria: un acercamiento al teatro de Laila Ripoll”. Hispanic Research Journal 17.4, 339-355 (también en http://dx.doi.org/10.1080/14682737.2016.1200859 [20/04/2017]).

AZCUE, V. (2009). "Antígona en el teatro español contemporáneo". Acotaciones 23, 33-46 (también en http://www.resad.es/acotaciones/ acotaciones 23/23 azcue.pdf [20/04/2017]).

AZNAR SOLER, M. (1991). “;Ay, Carmela!”. En Ñaque o de piojos y actores / ¡Ay, Carmela!, J. Sanchis Sinisterra, 57-101. Madrid: Cátedra.

BERNECKER, W. L. (2009). “"Memorias históricas' en España - debates y desarrollos recientes". En Debates sobre la memoria histórica en España. Beiträge zu Geschichte, Literatur und Didaktik, W. Altmann, W. L. Bernecker y U. Vences (eds.), 15-40. Berlín: tranvía / Walter Frey.

BERNINGER, M. (2006). Neue Formen des Geschichtsdramas in Großbritannien und Irland seit 1970. Trier: WVT.

BUNDGÅRD, A. (2000). “Antígona: figura alegórica del exilio". En Más allá de la filosofía. Sobre el pensamiento filosófico-místico de María Zambrano, 293-306. Madrid: Trotta.

CÉSPEDES, J. (2015). La obra de Jorge Semprún. Claves de interpretación. Vol. II: Cine y teatro. Berna: Peter Lang.

COLMEIRO, J. (2011). "A Nation of Ghosts? Haunting, Historical Memory and Forgetting in Post-Franco Spain". 452 ${ }^{\circ} \mathrm{F} 4,17-34$ (también en http://www.452f.com/pdf/numero04/colmeiro/04_452f_ mono_colmeiro_indiv.pdf [20/04/2017]).

DERRIDA, J. (1993). Spectres de Marx: l'État de la dette, le travail du deuil et la nouvelle Internationale. París: Galilée.

FISCHER-LICHTE, E. [1990] (2002). History of European Drama and 
Theatre, J. Riley (ed.). London: Routledge.

FLOECK, W.; FRITZ, H. y GARCÍA MARTÍNEZ, A. (eds.) (2008). Dramaturgias femeninas en el teatro español contemporáneo: entre pasado y presente. Hildesheim: George Olms.

FRANCIS, D.; KELLAHER, L. y NEOPHYTOU, G. (2005). The Secret Cemetery. Oxford: Berg.

GABRIELE, J. P. (2006). "Plotting Postmodern Being in Itziar Pascual's Père Lachaise". Studia Neophilologica 78, 165-175.

GARCÍA-MANSO, L. (2013). Género, identidad y drama histórico escrito por mujeres en España (1975-2010). Oviedo: KRK.

(2014). "Los fantasmas en el teatro de Itziar Pascual: memoria y construcción identitaria”. Brumal. Revista de Investigación sobre lo Fantástico 2.2, 87-107 (también en http://dx.doi.org/10.5565/rev/ brumal.124 [20/04/2017]).

GARCÍA-PASCUAL, R. (2014). "Las protagonistas del exilio republicano en la escena española del siglo XXI: una aproximación”. En Género y exilio teatral republicano: entre la tradición y la vanguardia, $\mathrm{F}$. Vilches de Frutos, P. Nieva de la Paz, J. R. López García y M. Aznar Soler (eds.), 223-236. Amsterdam/ Nueva York: Rodopi.

GENNEP, A. van [1909] (1960). The Rites of Passage. M. B. Vizedom y G. L. Caffee (eds.). Chicago: University of Chicago Press.

GORDON, A. F. (2008). Ghostly Matters. Haunting and the Sociological Imagination. Minneapolis: University of Minnesota.

GUTIÉRREZ CARBAJO, F. (1999). "Algunas adaptaciones fílmicas del teatro histórico". En Teatro histórico (1975-1998). Textos y representaciones, J. Romera y F. Gutiérrez Carbajo (eds.), 265-297. Madrid: Visor Libros.

HABEGGER, K. A. (1989). The Historical Drama in Spain during the Postwar and the Transition to Democracy. Michigan: UMI.

HALSEY, M. (1998). "Dramatic Patterns in Three History Plays of Contemporary Spain". Hispania 71.1, 20-30.

HÜTTMANN,A. (2001). Die Ästhetik der Geschichte. Das zeitgenössische historische Drama Spaniens im Spannungsfeld zwischen Sinn und Spiel. Tübingen: Francke.

LABANYI, J. (2000). "History and Hauntology; or, What Does One Do with the Ghosts of the Past? Reflections on Spanish Film and Fiction of the Post-Franco Period". En Disremembering the Dictatorship: 
the Politics of Memory in the Spanish Transition to Democracy, J. R. Resina (ed.), 65-82. Amsterdam: Rodopi.

MANGER, K. (1999). "Jorge Semprún's Bleiche Mutter, zarte Schwester - ein Oratorium”. En Jura Soyfer (1912-1939) zum Gedenken, H. Arlt y K. Manger (eds.), 336-346. St. Ingbert: Röhrig Universität.

NIETO, F. (2014). La aventura comunista de Jorge Semprún. Exilio, clandestinidad y ruptura. Barcelona: Tusquets.

NIEVA DE LA PAZ, P. (1999). "La tumba de Antígona (1967): teatro y exilio en María Zambrano". En El exilio teatral republicano de 1939, M. Aznar Soler (ed.), 287-301. Barcelona: GEXEL.

(1997). "Mito e historia: tres dramas de escritoras españolas en el exilio". Hispanistica XX 15, 123-131.

OGANDO, I. (2004). Teatro histórico. Construción dramática e construción nacional. A Coruña: Universidade da Coruña.

PINO CAMPOS, L. M. (2005). "Una Antígona inmortal: recreación zambraniana del personaje de Sófocles". En Estudios sobre María Zambrano: el magisterio de Ortega y las raíces grecolatinas de su filosofia, 415-431. La Laguna: Universidad.

PLAZA AGUDO, I. (2009). "La tumba de Antígona: un testimonio del exilio como categoría histórica y existencial". En Actas del Primer Congreso Internacional Las mujeres en la Esfera pública. Filosofía e historia contemporánea, L. Branciforte, C. González Marín, M. Huguet y R. Orsi (eds.), 355-379. Madrid: CERSA.

RAGUÉ-ARIAS, M.-J. (2005). "Del mito contra la dictadura al mito que denuncia la violencia y la guerra". En Mitos e identidades en el teatro español contemporáneo, F. Vilches de Frutos (dir.), 11-22. Amsterdam / Nueva York: Rodopi.

RECK, I. (2012). "El teatro grotesco de Laila Ripoll, autora”. Signa 21, 55-84 (también en http://revistas.uned.es/index.php/signa/article/ view/6300/6033 [20/04/2017]).

RESINA, J. R. (ed.) (2000). Disremembering the Dictatorship. The Politics of Memory in the Spanish Transition to Democracy. Amsterdam: Rodopi.

RIPOLL, L. (2010). Los niños perdidos, F. Vilches de Frutos (ed.). Oviedo: KRK.

RODRÍGUEZ RICHART, J. (2012). "Visión y sentido de la historia en el teatro español contemporáneo (especialmente de la "Generación 
Realista")". En Teatro español e hispánico. Siglo XX, J. Rodríguez Richart, 227-257. Madrid: Verbum.

ROMERA CASTILLO, J. (2008). "De la Historia a la memoria: recursos mitológicos y autobiográficos en algunas dramaturgas españolas del exilio". En Dramaturgias femeninas en el teatro español contemporáneo: entre pasado y presente, W. Floeck, H. Fritz y A. García Martínez (eds.), 123-137. Hildesheim: George Olms.

ROMERA CASTILLO, J. (ed.) (2003). Teatro y memoria en la segunda mitad del siglo XX. Madrid: Visor Libros.

ROMERA CASTILLO, J. y GUTIÉRREZ CARBAJO, F. (eds.) (1999). Teatro histórico (1975-1998). Textos y representaciones. Madrid: Visor Libros.

RUIZ RAMÓN, F. (1978). "Introducción al drama histórico contemporáneo". En Estudios de teatro español y contemporáneo, F. Ruiz Ramón, 215-142. Madrid: Fundación Juan March / Cátedra. SANCHIS SINISTERRA, J. (1991). Ñaque o de piojos y actores. ;Ay, Carmela!, M. Aznar Soler (ed.). Madrid: Cátedra.

SEMPRÚN, J. (1998). Le retour de Carola Neher. París: Gallimard. (2006). Pensar en Europa, J. Ramoneda (ed.). Barcelona: Tusquets. SERRANO, V. (1998). "El teatro histórico de José Sanchis Sinisterra en la frontera de los tiempos". En Théâtre et territoires - Espagne et Amérique Hispanique. 1950-1996. Teatro y territorios - España e Hispanoamérica, S. Bonnardel y G. Champeau (eds.), 71-81. Bordeaux: Maison des Pays Ibériques.

SOUTO, L. C. (2014). "El teatro español sobre apropiación de menores. La puesta en escena como espacio de identidad y memoria". $452^{\circ} \mathrm{F}$ 10, 50-66 (también en http://www.452f.com/pdf/numero10/10_452fmono-luz-c-souto-orgnl.pdf [20/04/2017]).

SPANG, K. (ed.) (1998). El drama histórico. Teoría y comentarios. Pamplona: EUNSA.

TURNER, V. [1969] (2008). The Ritual Process: Structure and AntiStructure. New Brunswick: Aldine Transaction.

(1982). From Ritual to Theatre: The Human Seriousness of Play. New York: PAJ.

TRUEBA MIRA, V. (2012). "Introducción”. En La tumba de Antígona $y$ otros textos sobre el personaje trágico, M. Zambrano, 9-138. Madrid: Cátedra. 
VILCHES DE FRUTOS, F. (1983). "Introducción al estudio de la recreación de los mitos literarios en el teatro de la postguerra española". Segismundo 37-38, 183-209.

(1999). "Teatro histórico: la elección del género como clave de la escena española contemporánea”. En Teatro histórico (1975-1998). Textos y representaciones, J. Romera Castillo y F. Gutiérrez Carbajo (eds.), 73-92. Madrid: Visor Libros.

(2006). "Mitos y exilios en la construcción de la identidad colectiva: Antígona en el teatro español contemporáneo". Hispanistica XX 24, 71-93.

(2010). "Entre tumbas, desvanes y tejados: los espacios de la memoria histórica en el teatro español contemporáneo". En Los niños perdidos, L. Ripoll, 11-29. Oviedo: KRK.

ZAMBRANO, M. " (1996). "Delirio de Antígona". En La Cuba secreta y otros ensayos, 98-106. Madrid: Endymión.

(2012). La tumba de Antígona y otros textos sobre el personaje trágico, V. Trueba Mira (ed.). Madrid: Cátedra.

Recibido el 12 de mayo de 2017.

Aceptado el 7 de junio de 2017. 
